\title{
Characterization of individual retained austenite grains and their stability in low-alloyed TRIP steels
}

\author{
E. Jimenez-Melero ${ }^{\text {a,* }}$, N.H. van Dijk ${ }^{\text {a }}$, L. Zhao ${ }^{\text {b }}$, J. Sietsma ${ }^{\text {b }}$, S.E. Offerman ${ }^{b}$, \\ J.P. Wright ${ }^{\mathrm{c}}$, S. van der Zwaag ${ }^{\mathrm{d}}$ \\ a Fundamental Aspects of Materials and Energy, Faculty of Applied Sciences, Delft University of Technology, Mekelweg 15, 2629 JB Delft, The Netherlands \\ ${ }^{\mathrm{b}}$ Department of Materials Science and Engineering, Delft University of Technology, Mekelweg 2, 2628 CD Delft, The Netherlands \\ ${ }^{c}$ European Synchrotron Radiation Facility, 6 Rue Jules Horowitz, BP 220, 38043 Grenoble Cedex, France \\ ${ }^{\mathrm{d}}$ Faculty of Aerospace Engineering, Delft University of Technology, Kluijverweg 1, 2629 HS Delft, The Netherlands
}

Received 9 July 2007; received in revised form 20 August 2007; accepted 20 August 2007

Available online 22 October 2007

\begin{abstract}
In situ three-dimensional (3-D) X-ray diffraction experiments have been performed at a synchrotron source on low-alloyed multiphase TRIP steels containing $0.25 \mathrm{wt} . \% \mathrm{Si}$ and $0.44 \mathrm{wt} . \% \mathrm{Al}$ and produced with different bainitic holding times, in order to assess the influence of the bainitic transformation on the thermal stability of individual austenite grains with respect to their martensitic transformation. A detailed characterization of the austenite grain volume distribution at room temperature was performed as a function of the prior bainitic holding time. In addition, the martensitic transformation behaviour of individual metastable grains was studied in situ during cooling to a temperature of $100 \mathrm{~K}$. Both the carbon content and the grain volume play a key role in the stability of the austenite grains below $15 \mu^{3}$, while the carbon content exerts the dominant effect in the stability of the bigger grains. Measurements also suggest that the tetragonality of the thermally formed martensite is suppressed.
\end{abstract}

(C) 2007 Acta Materialia Inc. Published by Elsevier Ltd. All rights reserved.

Keywords: TRIP steels; Polyphase microstructure; Metastable phases; Martensitic phase transformation; Synchrotron radiation

\section{Introduction}

The technological demands for new materials that fulfil very strict mechanical requirements trigger the design of novel composite microstructures of increasing complexity. New multiphase steels with improved mechanical properties have come into existence in the last years as a result of an intelligent combination of the chemical composition and industrial processing routes. The presence of metastable phases in the multiphase microstructure that transform into a hard martensite phase under external stresses has provided the steel producers with new possibilities to obtain extraordinary combinations of mechanical properties [1]. This applies to modern low-alloyed multiphase

\footnotetext{
* Corresponding author. Tel.: +31 15 2781192; fax: +31 152788303 .

E-mail address: E.Jimenez-Melero@tudelft.nl (E. Jimenez-Melero).
}

TRIP steels, which attract an increasing industrial and technological interest due to their appealing combination of high strength and formability [2-4]. The Transformation Induced Plasticity (TRIP) effect, which refers to the increase in plasticity caused by the martensitic transformation of the metastable austenite phase, was reported several decades ago to have beneficial consequences for the mechanical properties of expensive high-alloyed $\mathrm{Ni}-\mathrm{Cr}$ metastable austenitic steels [5]. However, modern alloy design on the basis of C-Mn steels indicates that the retention of small amounts of metastable austenite (less than 20 vol.\%.) at room temperature, coupled with the compositelike characteristics of the multiphase microstructure, leads to an outstanding combination of strength and formability at relatively low cost.

Modern low-alloyed TRIP steels make use of both carbon enrichment as well as the strong effect of carbon on 
austenite stability, in order to retain a significant amount of austenite in a metastable state at room temperature. To reach the desired microstructural starting state, a proper selection of alloying elements and a relatively complex two-step process route are required. The steel is initially intercritically annealed to yield an austenite-ferrite microstructure. At this stage, a certain degree of carbon enrichment of austenite is achieved. Then, the two-phase material is quenched to the temperature region where part of the austenite transforms into upper bainite. In this process, carbon will diffuse into the austenite phase, leading to a further increase in its carbon enrichment. The presence of certain alloying elements in the TRIP material (namely, silicon, aluminium or phosphorus) significantly retards the precipitation of cementite $\left(\mathrm{Fe}_{3} \mathrm{C}\right)$ within the austenite phase [6-8]. Consequently, the carbon concentration in solution remains high and the remaining austenite does not transform into martensite during the final quenching to room temperature. The resultant multiphase microstructure of TRIP steels at room temperature thus consists of three phases: intercritical ferrite, bainite and metastable austenite. For short bainitic holding times, some martensite might also be present in the microstructure $[9,10]$.

Great efforts have been devoted in the last years to obtain TRIP steels with an optimized stability of the metastable austenite, and attempts have been made to assess the contribution of the strain-induced martensitic transformation of austenite to the macroscopic mechanical response of the TRIP steel. Experimental studies have predominantly aimed at quantifying the austenite volume fraction and its average carbon concentration, and determining how the amount of austenite decreases during deformation of the material [3,11-15]. However, the stability of austenite is strongly influenced by other microstructural factors such as the grain size and morphology, the local stress state, the grain orientation and the nature of the surrounding multiphase matrix [10,16-19]. Therefore, new detailed microstructural information at the level of the individual grains is required to accurately control the austenite stability and its transformation behaviour into martensite during plastic deformation, giving rise to an improved combination of ductility and strength in TRIP steels.

We have recently been able to monitor in situ the martensitic transformation of individual austenite grains embedded in the complex multiphase TRIP microstructure, with the state-of-the-art 3-D synchrotron X-ray diffraction microscope [20]. The results obtained have allowed us to separately quantify the influence of both the local carbon content and the grain size on the thermal stability of the individual austenite grains, characterized by their martensitic transformation temperature. This opens the door to a new understanding of the stability of the austenite phase in low-alloyed multiphase TRIP steels. However, this study [20] was performed only for one TRIP steel with a selected chemical composition and fixed processing conditions. The aim of the present paper is to extend these results on the stability of metastable austenite to a broader range of local carbon content and grain volume distributions, and to relate those distributions to industrial process conditions. For this purpose, four TRIP microstructures with the same chemical composition but produced with different bainitic holding times have been studied. In this way, a clear link between the characteristics of the bainitic transformation of the intercritical austenite phase, which constitutes a key step in the industrial process of TRIP steels, and the stability of the retained austenite grains at room temperature is established. Furthermore, the results of the present paper also constitute a key input for the current development of micromechanical models of the martensitic transformation in multiphase TRIP steels for different microstructural characteristics of the metastable austenite phase and its local surrounding matrix $[19,21,22]$.

\section{Experimental}

The chemical composition of the TRIP steel in this study was: 0.188 wt. $\%$ C, 1.502 wt. $\% \mathrm{Mn}, 0.254$ wt.\% Si, 0.443 wt. $\%$ Al, 0.015 wt. \% P and balance Fe. Cylindrical samples with a diameter of $0.50 \mathrm{~mm}$ and a length of 2.0 $\mathrm{mm}$ were machined from the hot-rolled sheet material. The cylindrical axis of the samples was selected to be parallel to the rolling direction of the sheet material. The samples were intercritically annealed in a salt bath at $1073 \mathrm{~K}$ for $30 \mathrm{~min}$, to obtain a two-phase material containing 37 vol.\% of austenite within a ferritic matrix [23]. They were subsequently transferred to a second salt bath kept at a temperature of $673 \mathrm{~K}$, where part of the intercritical austenite phase transformed into carbide-free bainite. The bainitic holding time was varied systematically $(20$, 60,240 and $1000 \mathrm{~s}$ ) to yield different microstructural characteristics of the remaining carbon-enriched austenite [13]. The samples were finally quenched in water to room temperature.

The resultant room-temperature multiphase microstructures were characterized using an intense monochromatic microbeam of high-energy X-rays. The experiments were performed at the 3-D X-ray diffraction microscope present at the ID11 beam line of the European Synchrotron Radiation Facility (Grenoble, France). Fig. 1 shows a schematic representation of the experimental setup used for these experiments. A monochromatic X-ray beam with an energy of $80 \mathrm{keV}$ (wavelength of $0.155 \AA$ ) and a beam size of $28 \times 29 \mu \mathrm{m}^{2}$ illuminated the cylindrical sample. The high energy of the X-ray beam made it possible to study the diffracted beam after transmission through the cylindrical samples with a diameter of $0.5 \mathrm{~mm}$. The diffracted intensity was recorded on a two-dimensional (2-D) detector placed behind the sample. During an exposure time of $2 \mathrm{~s}$, the sample was continuously rotated around its cylindrical axis over an angle of $\Delta \omega=0.5^{\circ}$. In a series of exposures, the initial $\omega$-position was varied from -30 to $+30^{\circ}$. The grains that fulfilled the Bragg condition generated a diffraction spot on the 2-D detector. Due to the micrometer dimensions of the X-ray beam and the limited angular rotation 


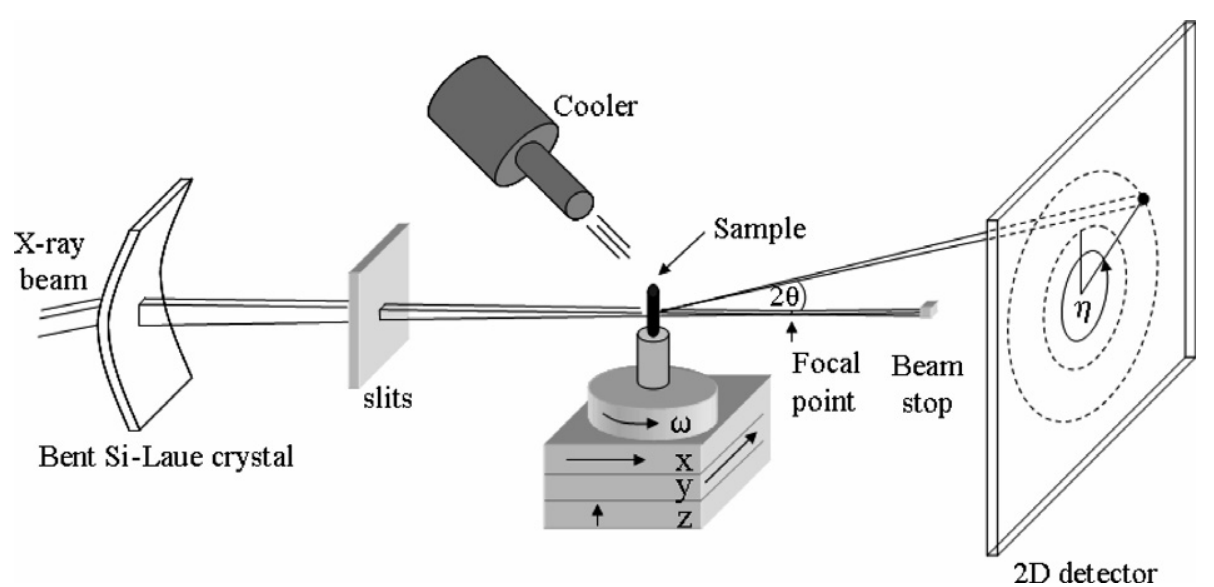

Fig. 1. Schematic representation of the experimental setup used for the 3DRXD experiments on low-alloyed multiphase TRIP steels. A monochromatic beam of high-energy X-rays defined by the slits illuminates the cylindrical sample. The diffracted intensity is collected on the 2-D detector. The sample is mounted on a table that can be translated in three dimensions and rotated along the cylindrical axis of the sample. A nitrogen gas cryostream cooler allows to cool the sample from room temperature down to $100 \mathrm{~K}$.

for each exposure, separate diffraction spots appear within the austenite and ferrite diffraction rings. Additional scans were performed with a larger beam size of $39 \times 39 \mu \mathrm{m}^{2}$, to test whether the grains were completely illuminated by the X-ray beam.

In order to study the stability of the metastable austenite grains present in the microstructure at room temperature, the TRIP samples were cooled from room temperature to $100 \mathrm{~K}$ in steps of $20 \mathrm{~K}$ with the help of a nitrogen gas cryostream cooler (Oxford Cryosystems). In this way, we thermally induced the martensitic transformation of the austenite grains by increasing the chemical driving force for the transformation. In the present study, we have chosen to induce the martensitic transformation by a cooling process instead of an external stress due to its improved experimental accuracy. After each temperature step, the same illuminated sample volume was retraced by performing scans of the horizontal sample position, the vertical sample position and the sample rotation angle. For this purpose, the intensity of a selected diffraction spot from a characteristic non-transforming ferrite grain was used. After this sample repositioning at each temperature, the diffraction pattern was recorded for each exposure during the $\omega$-scan for the two mentioned beam sizes. After reaching the lowest temperature of $100 \mathrm{~K}$, the samples were heated back to room temperature, at which diffraction patterns for the two beam sizes were also recorded for a direct comparison of the room-temperature microstructures before and after cooling.

\section{Results and discussion}

\subsection{Characteristics of austenite at room temperature}

Fig. 2 displays a 2-D diffraction pattern of TRIP steel at room temperature. From this diffraction pattern, the $\{200\},\{220\}$ and $\{311\}$ austenite reflections (face-centered cubic (fcc) structure) and the $\{200\},\{211\}$ and
$\{220\}$ ferrite reflections (body-centred cubic (bcc) structure) have been analysed in detail. Each austenite diffraction ring consists of a number of single spots originating from individual austenite grains in the TRIP microstructure, together with a powder signal stemming from austenite grains whose volume falls below the experimental detection limit for individual grains estimated to be about $5 \mu \mathrm{m}^{3}$ [24]. The integrated intensity of each single diffraction spot, distributed over a number of diffraction patterns in the covered $\omega$-range, is directly proportional to the volume of the grain from which it originates [24,25]. Moreover, by performing a peak fit it was possible to determine not only the grain volume $\left(V_{\gamma}\right)$, but also the lattice parameter $\left(a_{\gamma}\right)$ and hence the carbon content $\left(x_{\mathrm{C}}\right)$, of the individual austenite grains. The relationship between the austenite lattice parameter and the grain's chemical composition used in the present study is $[23,26]$ :

$a_{\gamma}=3.556+0.0453 x_{\mathrm{C}}+0.00095 x_{\mathrm{Mn}}+0.0056 x_{\mathrm{Al}}$

where $a_{\gamma}$ is in $\AA$ and $x_{\mathrm{C}}, x_{\mathrm{Mn}}$ and $x_{\mathrm{Al}}$ are in wt.\%. The presence of silicon does not significantly influence the austenite lattice parameter within experimental accuracy [27]. In the analysis, the overall content of $\mathrm{Mn}$ and $\mathrm{Al}$ is assumed to be present in each austenite grain. The uncertainty in the determination of the carbon content from the austenite lattice parameter due to the beam size and the sample thickness corresponds to only $0.02 \mathrm{wt} . \%$ in these experiments.

Recent electron microscopy studies have revealed the presence of two types of austenite grains of different size and morphology in TRIP steels, as a consequence of the bainitic transformation $[10,28]$ : very fine "film-type" austenite grains located between the bainitic plates, and larger "blocky-type" austenite grains which constitute the remaining parts of the intercritical austenite grains after the partial bainitic transformation. Only the latter type of austenite grains have a volume larger than the experimental detection limit for individual grains of $5 \mu \mathrm{m}^{3}$. Both the carbon content and the volume of a significant number of 

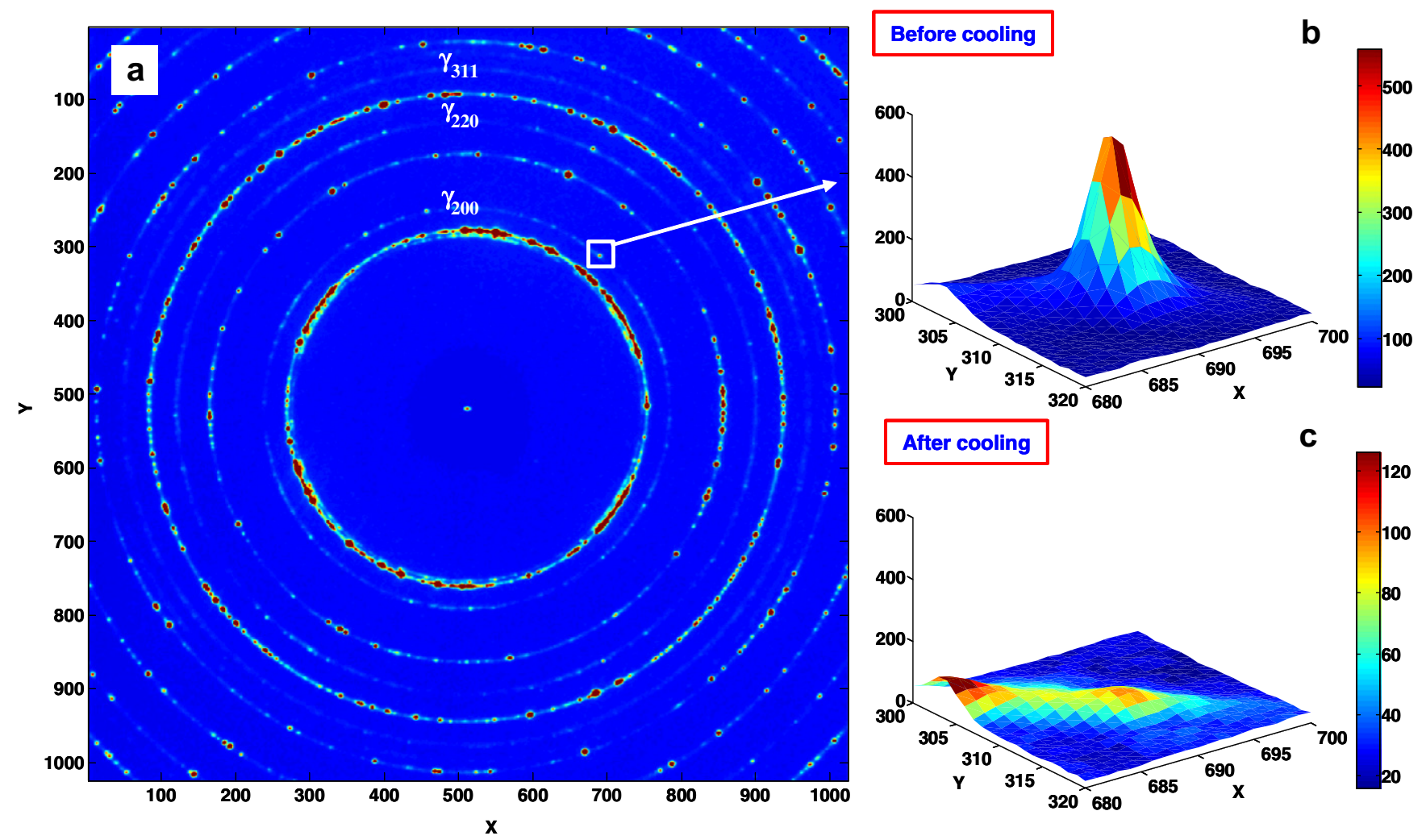

Fig. 2. X-ray diffraction pattern of TRIP steel. (a) Complete 2-D diffraction pattern at room temperature. The $\{200\},\{220\}$ and $\{311\}$ austenite diffraction rings are indicated in the figure as $\gamma_{200}, \gamma_{220}$, and $\gamma_{311}$, respectively. (b) A single austenite diffraction peak from the $\{200\}$ ring at room temperature before cooling. (c) The same region as in (b) after cooling the sample to $100 \mathrm{~K}$ and heating back to room temperature (taken from Ref. [20]).

these larger "blocky-type" austenite grains have been determined for each of the four samples with different bainitic holding times. Fig. 3 displays the histograms of the number of grains as a function of the carbon content and grain volume. As the bainitic transformation proceeds, more intercritical austenite grains are progressively consumed, and therefore the remaining austenite grains are expected to have a smaller grain size and a higher carbon enrichment. These trends are reflected in the shape of the distributions: a decaying tail towards large grain volumes, and a low density of low carbon-content grains. However, the number of austenite grains present at room temperature in these TRIP samples increases from a bainitic holding time of $20 \mathrm{up}$ to $240 \mathrm{~s}$, and then decreases from 240 to $1000 \mathrm{~s}$ (Table 1). In fact, there are no austenite grains with a volume bigger than $20 \mu \mathrm{m}^{3}$ present for a bainitic holding time of $20 \mathrm{~s}$, while there is a substantial number of grains between 20 and $50 \mu \mathrm{m}^{3}$ for a bainitic holding time of $240 \mathrm{~s}$. Moreover, the average grain size estimated from the size distribution turns out to be smaller for 20 and $60 \mathrm{~s}$ than the one for $240 \mathrm{~s}$ (see Table 1). This indicates that for bainitic transformation times of 20 and $60 \mathrm{~s}$, a part of the austenite grains are not stable enough to withstand the transformation into martensite during the quenching of the TRIP material from $673 \mathrm{~K}$ down to room temperature. In contrast, the absence of austenite grains with a volume bigger than $20 \mu \mathrm{m}^{3}$ in the sample of $1000 \mathrm{~s}$ can be ascribed to their bainitic transformation at $673 \mathrm{~K}$. While the austenite grains at room temperature in the $20 \mathrm{~s}$ sample present an average carbon concentration of $0.81 \mathrm{wt} . \%$, the austenite grains retained in the $1000 \mathrm{~s}$ sample are further enriched in carbon to yield an average concentration of $1.18 \mathrm{wt} . \%$ (Table 1), whereas the grain volume distributions for the two microstructures are very similar. Therefore, the austenite grains present in the $20 \mathrm{~s}$ sample are stabilized mainly due to their small grain size, while both the grain volume and the carbon enrichment contribute significantly to the stabilization of the austenite grains in the TRIP microstructure of the $1000 \mathrm{~s}$ sample at room temperature.

Furthermore, the average carbon content increases from 240 to $1000 \mathrm{~s}$, indicating that the remaining austenite grains are not depleted in carbon at longer bainitic holding times due to the precipitation of carbides. This observation is supported by the absence of $\mathrm{Fe}_{3} \mathrm{C}$ reflections in the 2-D diffraction patterns at room temperature for all bainitic holding times up to $1000 \mathrm{~s}$. The presence of $0.254 \mathrm{wt} . \% \mathrm{Si}$ and 0.443 wt.\% $\mathrm{Al}$ in this TRIP material effectively hinders the formation of carbides during the holding step at $673 \mathrm{~K}$, so that the intercritical austenite will not undergo any further bainitic transformation when its carbon enrichment reaches the limit established by the $T_{0}$-curve [29]. Recent 3-D atom probe measurements did not reveal the occurrence of long-range diffusion of substitutional elements during the incomplete bainite transformation. This 

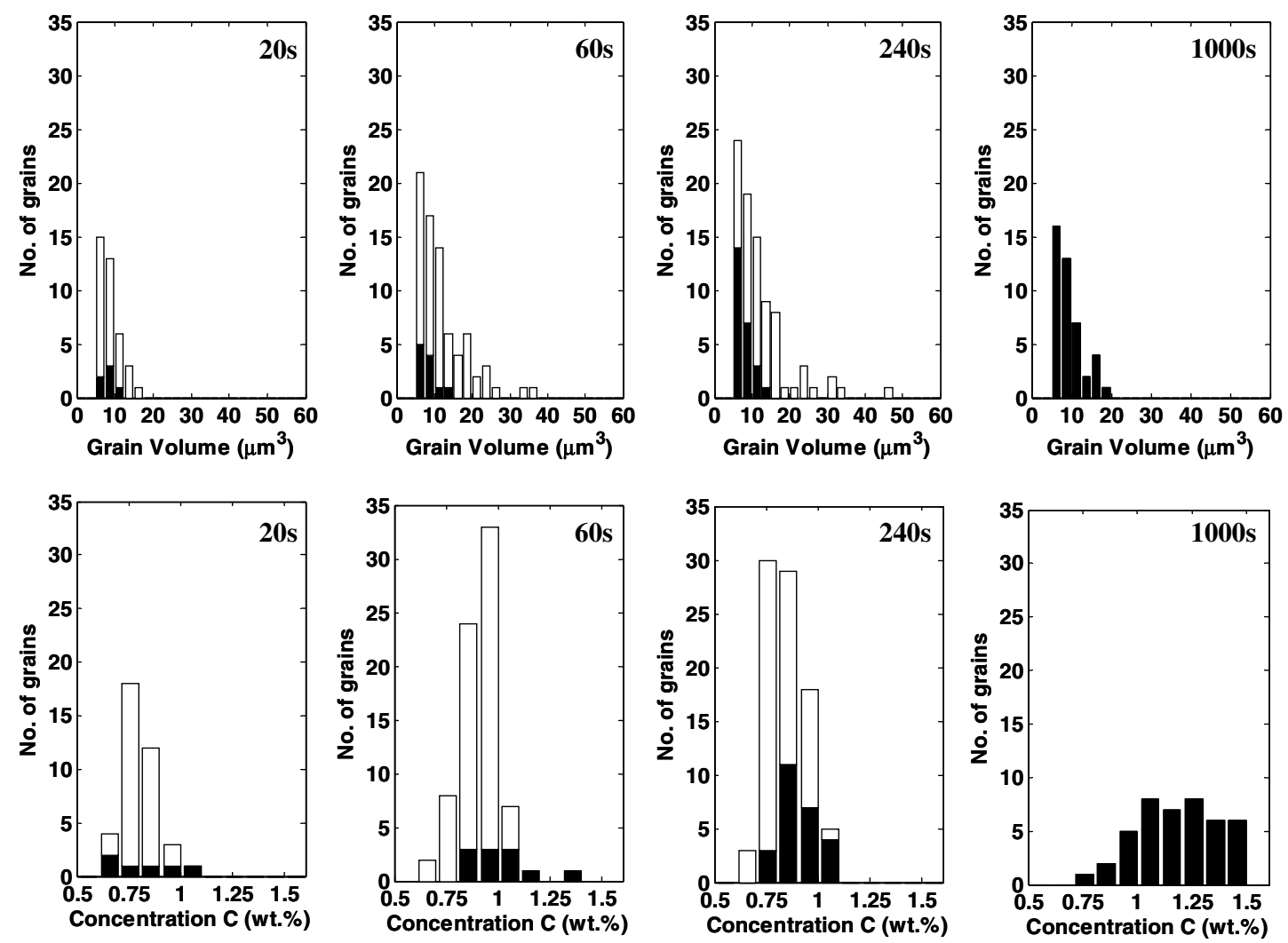

Fig. 3. Number of austenite grains above the detection limit for individual grains of $5 \mu \mathrm{m}^{3}$ at room temperature, as a function of the grain volume and carbon concentration for four different bainitic holding times (20,60, 240 and $1000 \mathrm{~s})$. The white bars correspond to the grain distribution before cooling, while the black bars represent the grain distribution after having cooled the TRIP material down to $100 \mathrm{~K}$ and heated it back to room temperature. Both distributions at room temperature coincide in the case of the bainitic holding time of $1000 \mathrm{~s}$.

Table 1

Total number of grains $\left(N_{\gamma}\right)$, average grain volume $\left(\left\langle V_{\gamma}\right\rangle\right)$ and carbon concentration $\left(\left\langle X_{\mathrm{C}}\right\rangle\right)$ of the austenite grain distribution at room temperature (before and after cooling the TRIP material to $100 \mathrm{~K}$ ) as a function of the bainitic holding time

\begin{tabular}{|c|c|c|c|c|c|c|}
\hline \multirow[t]{2}{*}{$t_{\mathrm{bh}}(\mathrm{s})$} & \multicolumn{2}{|l|}{$N_{\gamma}$} & \multicolumn{2}{|c|}{$<V_{\gamma}>\left(\mu \mathrm{m}^{3}\right)$} & \multicolumn{2}{|c|}{$<X_{\mathrm{C}}>($ wt. $\%)$} \\
\hline & Before & After & Before & After & Before & After \\
\hline 20 & 38 & 6 & $8.7(2.8)$ & $8.2(2.1)$ & $0.81(0.08)$ & $0.84(0.14)$ \\
\hline 240 & 85 & 25 & $11.9(7.1)$ & $7.7(2.2)$ & $0.85(0.09)$ & $0.91(0.08)$ \\
\hline 1000 & 43 & 43 & $9.0(3.5)$ & $9.0(3.5)$ & $1.18(0.19)$ & $1.18(0.19)$ \\
\hline
\end{tabular}

The width of the distribution (standard deviation) is indicated in parenthesis.

indicates that the bainitic ferrite plates will have the same chemical composition as the parent intercritical austenite grains with respect to the substitutional elements like manganese, silicon and aluminium [30]. The presence of bainitic ferrite plates manifests itself as an increase in the powder signal within the ferrite rings, instead of producing additional separate Bragg reflections. Consequently, the carbon content in the bainitic ferrite plates is equivalent to the one in the intercritically formed ferrite grains. Once a bainite plate is nucleated and starts to grow, the carbon atoms diffuse out of the plate into the surrounding austenite grains. When the bainite plate stops growing, its carbon content is equivalent to the equilibrium carbon concentration for bcc iron.

\subsection{Characteristics of austenite at room temperature after cooling to $100 \mathrm{~K}$}

Once the initial metastable austenite phase at room temperature was characterized as a function of the bainitic holding time, the TRIP samples were cooled down to $100 \mathrm{~K}$ in order to study the stability of the austenite grains with respect to the martensitic transformation. Table 2 collects the total volume fraction of the austenite phase, together with the fraction of the austenite grains with a volume either bigger or smaller than $5 \mu \mathrm{m}^{3}$, before and after cooling the TRIP material to $100 \mathrm{~K}$. A powder analysis of the integrated intensity of the austenite and ferrite rings reveals that more than $20 \mathrm{vol} . \%$ of the metastable austenite 
Table 2

Total volume fraction of the austenite phase at room temperature as a function of the bainitic holding time before and after cooling the TRIP material to $100 \mathrm{~K}$ (taken from Ref. [23]), together with the volume fraction corresponding to the austenite grains whose volume is either above or below the experimental detection limit for individual grains of $5 \mu^{3}$

\begin{tabular}{llllc}
\hline & $20 \mathrm{~s}$ & $60 \mathrm{~s}$ & $240 \mathrm{~s}$ & $1000 \mathrm{~s}$ \\
\hline$f_{\gamma, \text { before }}^{\text {total }}(\%)$ & $6.32(7)$ & $7.49(5)$ & $6.01(5)$ & $4.12(5)$ \\
$f_{\gamma, \text { after }}^{\text {total }}(\%)$ & $4.95(5)$ & $4.97(4)$ & $4.73(4)$ & $3.98(3)$ \\
$f_{\gamma, \text { after }}^{\text {total }} / f_{\gamma, \text { before }}^{\text {total }}(\%)$ & 78 & 66 & 79 & 97 \\
$f_{\gamma, \text { after }}^{>5 \mu m^{3}} / f_{\gamma, \text { before }}^{>5 \mu m^{3}}(\%)$ & 15 & 10 & 19 & 100 \\
$f_{\gamma, \text { after }}^{<5 \mu m^{3}} / f_{\gamma, \text { before }}^{<5 \mu m^{3}}(\%)$ & 70 & 77 & 82 & 95 \\
\hline
\end{tabular}

phase at room temperature has transformed into martensite during cooling, with the exception of the $1000 \mathrm{~s}$ sample where virtually all the initial austenite remains untransformed after cooling. More details about the powder analysis can be found elsewhere [23]. An analysis of the volume fraction of the austenite grains bigger than $5 \mu^{3}$ in the $1000 \mathrm{~s}$ sample before and after cooling indicates that these grains are too stable due to their combination of high carbon enrichment and small grain size, so that none of them transforms into martensite during cooling to $100 \mathrm{~K}$. By contrast, less than $20 \mathrm{vol} \%$ of the larger grains remains untransformed during cooling for samples with a shorter bainitic holding time. The highest degree of transformation appears to take place in the $60 \mathrm{~s}$ sample. The anomalously high volume fraction of large grains remaining after cooling in the $20 \mathrm{~s}$ sample confirms the martensitic transformation of a significant number of austenite grains during the previous quenching from $673 \mathrm{~K}$ down to room temperature for the shortest holding time of $20 \mathrm{~s}$. Fig. 3 displays the grain distribution for each of the four bainitic holding times at room temperature after cooling to $100 \mathrm{~K}$, while the total number of grains and the average grain volume and carbon concentration are collected in Table 1, together with the width (standard deviation) of the distributions. It is noteworthy that the total number of austenite grains remaining untransformed after cooling increases with the bainitic holding time, as opposed to the number of grains before cooling that shows a maximum for the $240 \mathrm{~s}$ sample. In fact, all the grains with a volume larger than $20 \mu \mathrm{m}^{3}$ have transformed during cooling, and consequently the grain distributions have shifted to smaller volumes and have become less broad. Their average grain volume has been considerably reduced, and concomitantly the average carbon content has increased significantly after cooling for the 20, 60 and $240 \mathrm{~s}$ samples. These observations imply that only the austenite grains with the combination of a small volume and a high carbon concentration are stable enough to remain untransformed after the cooling process. These two microstructural parameters vary with the bainitic holding time, so that a longer time leads to a higher stability of the remaining austenite grains at room temperature.

Table 2 also shows the volume fraction of the austenite grains smaller than $5 \mu \mathrm{m}^{3}$ that remains untransformed after the cooling process, as derived from the analysis of the powder signal present in the austenite diffraction rings. The stability of these relatively small grains increases continuously with the bainitic holding time. The degree of transformation varies from $30 \%$ in the $20 \mathrm{~s}$ sample to only $5 \%$ for the longest holding time of $1000 \mathrm{~s}$. The austenite grains with a volume below $5 \mu \mathrm{m}^{3}$ correspond to all the "film-type" grains and a small amount of the "blockytype" grains. Recent studies on multiphase TRIP steels indicated that the "film-type" austenite grains present between the bainitic plates do not transform into thermally-induced martensite down to $100 \mathrm{~K}$ [20] nor into stress-induced martensite until the onset on necking $[17,28,31]$. These "film-type" grains were therefore not considered to contribute to the TRIP effect in these materials due to their extremely high stability. In the present study, the average carbon content of the relatively small grains turns out to be approximately $1.1 \mathrm{wt} . \%$. Such value is significantly lower than the $1.25 \mathrm{wt} . \%$ previously reported for a TRIP material with the higher aluminium content of 1.750 wt.\% [20]. The difference in stability can then be attributed to a lower carbon enrichment of the small "blocky-type" austenite grains when the aluminium content of the TRIP material is reduced to only $0.443 \mathrm{wt} . \%$. In this case, a long bainitic holding time is required in order to avoid any degree of transformation into martensite during cooling the material to $100 \mathrm{~K}$.

\subsection{Evidence of martensite formation}

As previously discussed, part of the metastable austenite will transform into martensite during cooling down to $100 \mathrm{~K}$. The martensitic plates will inherit the carbon content of the parent austenite grains. In the present study, the carbon levels in the martensitic plates vary from 0.6 to $1.2 \mathrm{wt} . \%$, depending on the degree of carbon enrichment of the parent austenite grains during the bainitic transformation at $673 \mathrm{~K}$ (see Fig. 3). An order-disorder transition of the carbon atoms within the octahedral interstitial sites of the bcc lattice is reported to take place at a certain carbon concentration ranging from 0.2 to $0.6 \mathrm{wt} . \%$ depending on the temperature [32]. In fact, the preferential distribution of the carbon atoms in one sublattice of the octahedral interstitial sites above a critical carbon concentration and below a certain temperature gives rise to a tetragonal distortion of the cubic lattice, resulting in a body-centred tetragonal lattice (bct). This distortion manifests itself in the lattice parameters of martensite $(a$ and $c$ ), which depend on the carbon content $\left(x_{\mathrm{C}}\right)$ according to [32]:

$c=a_{0}+\alpha x_{\mathrm{C}}, \quad a=a_{0}-\beta x_{\mathrm{C}}, \quad c / a=1+\gamma x_{\mathrm{C}}$

where $x_{\mathrm{C}}$ is in wt. $\%, a_{0}=2.8665 \AA$ corresponds to the lattice parameter of ferrite (bcc), $\alpha=0.116(2) \AA$ wt. $\%^{-1}$, $\beta=0.013(2) \AA \mathrm{wt} . \%^{-1}$ and $\gamma=0.046(1)(\mathrm{wt} . \%)^{-1}$. As a consequence of the tetragonal distortion, the diffraction peaks corresponding to the bcc structure undergo a significant splitting. For instance, the $\{200\}$ reflection (bcc) will give rise to the $\{002\}$ and $\{200\}$ reflections (bct). 
The expected splitting is well above the instrumental resolution.

In the present study, the experimentally measured values of the carbon content in the austenite grains, and therefore in the thermally induced martensite plates, are well above the reported critical carbon concentration for the tetragonal distortion to occur. Such distortion would also be favoured by the low temperatures of the experiments in the present study. Therefore, additional separate diffraction rings due to the newly formed martensite are expected to appear in the 2-D diffraction patterns as the parent austenite progressively transforms into martensite. However, the formation of martensite is only evidenced by an increase in the powder signal within the ferrite (bcc) diffraction rings from the intercritical and bainitic ferrite. This discrepancy points to the existence of a critical grain size below which the martensite tetragonal distortion is suppressed, since the reduction in the strain-induced elastic interaction energy will not dominate over the decrease in entropy associated with the ordering of the carbon atoms [33]. The recent evaluation of the synchrotron diffraction data taken during the strain-induced martensite formation at room temperature in low-alloyed multiphase TRIP steels with the same chemical composition as the TRIP material in the present study also failed to reveal the presence of the additional separate martensite diffraction rings [18]. The suppression of the tetragonal distortion of martensite below a critical size will be of importance for the micromechanical models of the martensitic transformation in multiphase TRIP steels that generally assume the occurrence of martensitic variants $[19,21,22]$.

\subsection{Martensitic transformation behaviour of the austenite grains during cooling to $100 \mathrm{~K}$}

By following the temperature dependence of the integrated intensity of the single diffraction spots, and hence the corresponding grain volume, the martensitic transformation of the individual austenite grains within the multiphase TRIP microstructure was monitored in situ. During each temperature step of $20 \mathrm{~K}$, a certain fraction of the initial austenite phase transforms into martensite. No timedependent isothermal transformation has been observed at any of the measured temperatures in either of the samples during these experiments, so that the microstructure is determined by the lowest temperature reached. Three different types of transformation behaviour of individual austenite grains during cooling were observed. Representative transformation curves are shown in Fig. 4. Most of the austenite grains transform into martensite during a single temperature step (Fig. 4a). A significant number of austenite grains remain stable down to the lowest temperature of $100 \mathrm{~K}$ (Fig. 4c). The fraction of one-step transforming grains reduces with increasing bainitic holding time from $80 \%$ in the $20 \mathrm{~s}$ sample to $0 \%$ in the sample with the longest holding time of $1000 \mathrm{~s}$ (see Table 3). In contrast, the fraction of non-transforming grains increases from 16 to
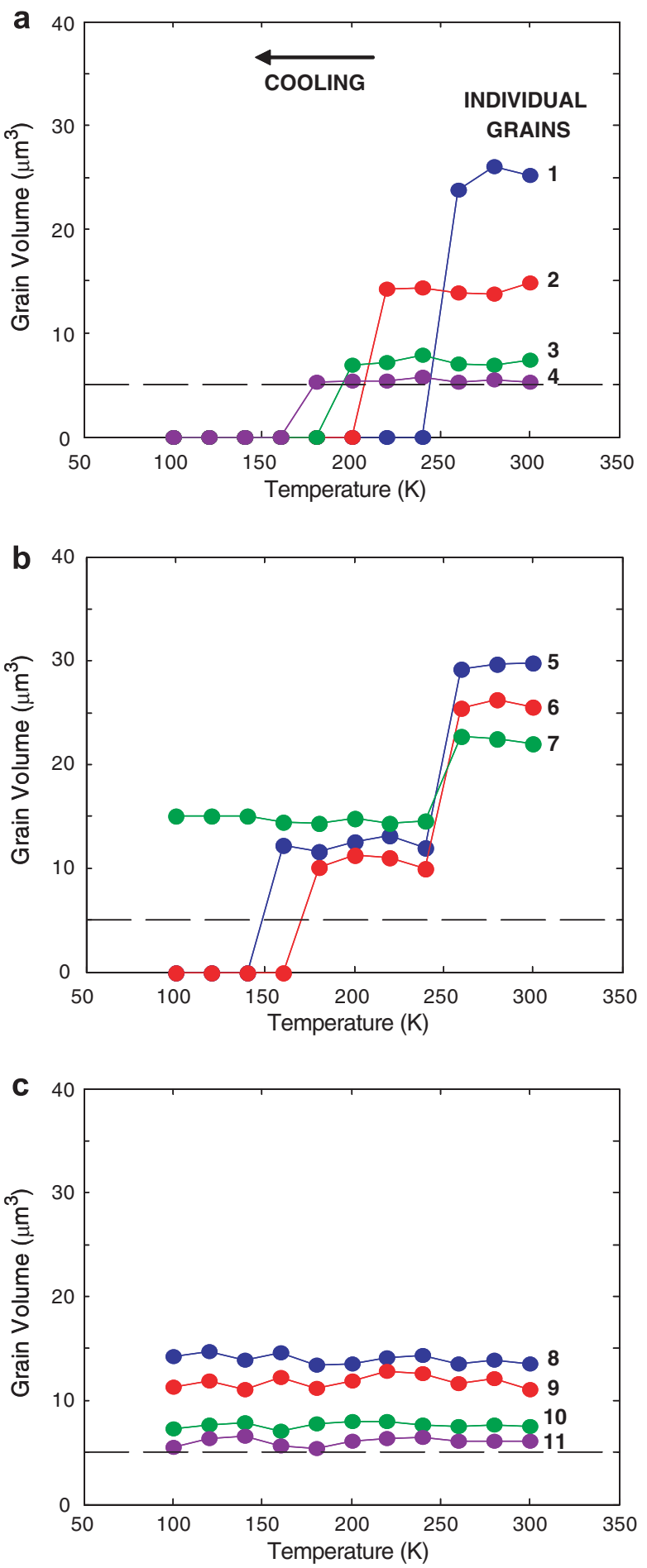

Fig. 4. Observed transformation behaviours of the individual austenite grains: (a) grains that transform completely into martensite in a single temperature step (1-4). (b) Grains that partly transform into martensite (5-7). For some of these grains, a second transformation is observed at lower temperature $(5,6)$. (c) Grains that remain untransformed down to $100 \mathrm{~K}(8-11)$. The dash lines indicate the experimental detection limit for individual grains.

$100 \%$ when the bainitic holding time is varied from 20 to $1000 \mathrm{~s}$. These observations indicate the increase in stability of the austenite grains retained at room temperature for 
Table 3

Number percentage $(\%)$ of individual austenite grains as a function of the bainitic holding time that presents the following transformation behaviours (see Fig. 4): one-step transformation (TYPE I), two-step or incomplete transformation (TYPE II), non-transforming grains (TYPE III)

\begin{tabular}{lcccc}
\hline & $\mathbf{2 0} \mathbf{s}$ & $\mathbf{6 0} \mathbf{s}$ & $\mathbf{2 4 0} \mathbf{s}$ & $\mathbf{1 0 0 0} \mathbf{s}$ \\
\hline TYPE I & 80 & 75 & 65 & 0 \\
TYPE II & 4 & 11 & 6 & 0 \\
TYPE III & 16 & 14 & 29 & 100 \\
\hline
\end{tabular}

increasing bainitic holding times. In addition, a small number of austenite grains in the 20,60 and $240 \mathrm{~s}$ samples undergoes an incomplete transformation. A second transformation at lower temperatures is observed in some of these grains (Fig. 4b).

The temperature dependence of the lattice parameter of the individual austenite grains is derived from the position of the corresponding diffraction spots at each temperature. Fig. 5 shows three illustrative examples of the lattice parameter of austenite grains between room temperature and $100 \mathrm{~K}$. In this temperature region, the thermal contraction of the austenite lattice parameter is given by [23]:

$\frac{a(T)-a(300)}{a(300)}=\int_{300}^{T} \alpha(T) d T$

where $a(300)$ is the austenite lattice parameter derived from the peak fit, and $\alpha(T)=A T$ the coefficient of thermal expansion with $A=5.3 \times 10^{-8} \mathrm{~K}^{-2}$. The thermal expansion at $T=300 \mathrm{~K}$ amounts to $\alpha(300)=16.0 \times 10^{-6} \mathrm{~K}^{-1}$ [23]. The lattice parameter of the non-transforming grains follows Eq. (3) down to $100 \mathrm{~K}$ (see Grain 9 in Fig. 5). The one-step transforming grains also comply with the thermal contraction until they transform into martensite.

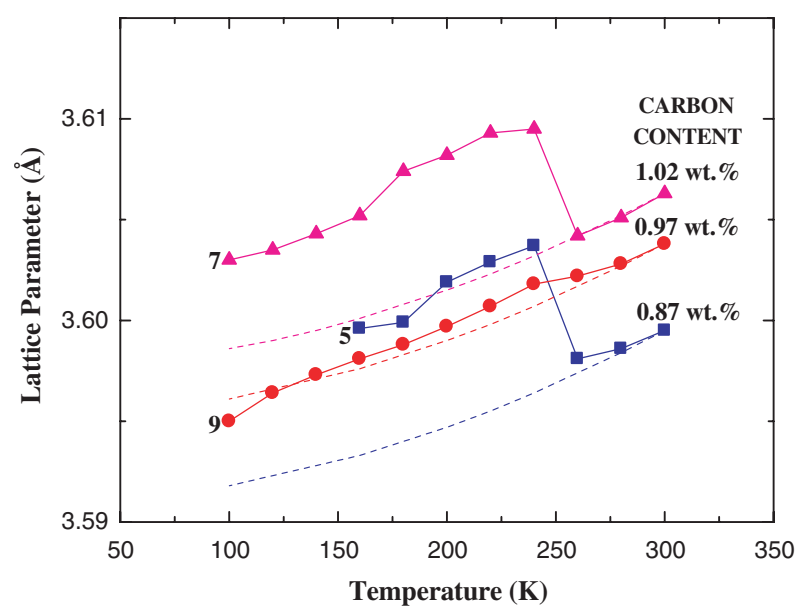

Fig. 5. Temperature dependence of the austenite lattice parameter of a two-step transforming grain (Grain 5), a grain showing an incomplete transformation (Grain 7), and a non-transforming austenite grain (Grain 9). The dashed lines corresponds to the thermal contraction (see Eq. (3)). The carbon content of each austenite grain, derived from the corresponding lattice parameter at room temperature $(a(300))$, is also indicated in the figure.
Only a small fraction of the austenite grains (less than $5 \%$ ) shows deviations from Eq. (3), which may be attributed to the occurrence of local strains during cooling due to the difference in thermal expansion between austenite and ferrite. The lattice parameter of the two-step or incomplete transformation grains present a clear upward jump when the first transformation step occurs during cooling (see Grains 5 and 7 in Fig. 5). This indicates that the remaining part at low temperatures has a higher carbon content compared with the part that transforms into martensite at higher temperatures.

The occurrence of the martensite transformation of the metastable austenite grains at different temperatures during cooling reveals a stability distribution within the austenite phase. The grains transforming at a higher temperature are less stable, while the grains remaining at $100 \mathrm{~K}$ are too stable to transform into martensite. The incomplete transformation and the two-step transformation behaviours (Fig. 4b) probably originate from two spatially separated parts of an original intercritical austenite grain that have experienced a different carbon enrichment and size development during the bainitic transformation at $673 \mathrm{~K}$. However, it cannot be excluded that these transformation behaviours stem from variations in stability within a single austenite grain, since the austenite grain is enriched in carbon to a larger extend in the immediate vicinity of the bainite plates, at least for the shorter bainitic holding times [29].

The stability of the individual austenite grains is characterized by the temperature at which they transform into martensite, namely the martensitic transformation temperature $\left(M_{\mathrm{S}}\right)$. This temperature can be related to the grain volume $\left(V_{\gamma}\right)$ and carbon content $\left(x_{\mathrm{C}}\right)$ of the austenite grain at room temperature before cooling. Therefore, each of the studied individual grains is characterized by a set of three parameters $\left(M_{\mathrm{S}}, V_{\gamma}, x_{\mathrm{C}}\right)$. Fig. 6 displays the austenite lattice parameter, and the corresponding carbon content, as a function of the grain volume at room temperature for the different bainitic holding times. There is an overall trend of increasing carbon content for decreasing grain volumes. Such a trend is specially noticeable in the $240 \mathrm{~s}$ sample, since most of the bigger grains present in the $20 \mathrm{~s}$ and $60 \mathrm{~s}$ samples right after the bainitic transformation at $673 \mathrm{~K}$ are too unstable, and transform into martensite during the quenching to room temperature (see Section 3.1). The larger austenite grains with the lower carbon content are less stable, and therefore transform at a higher temperature during cooling the material from room temperature to $100 \mathrm{~K}$. The relationship between the martensitic transformation temperature of the metastable austenite grains and their carbon content and grain size takes the form [20]:

$M_{\mathrm{S}}=M_{\mathrm{S} 0}-A x_{\mathrm{C}}-B V_{\gamma}^{-\frac{1}{3}}$

The first two terms of this expression reflect the wellknown Andrews' empirical relationship between $M_{\mathrm{S}}$ and the carbon content with $A=425 \mathrm{~K} \mathrm{wt} . \%^{-1}$ [34], while the third term was recently introduced to quantify the effect 

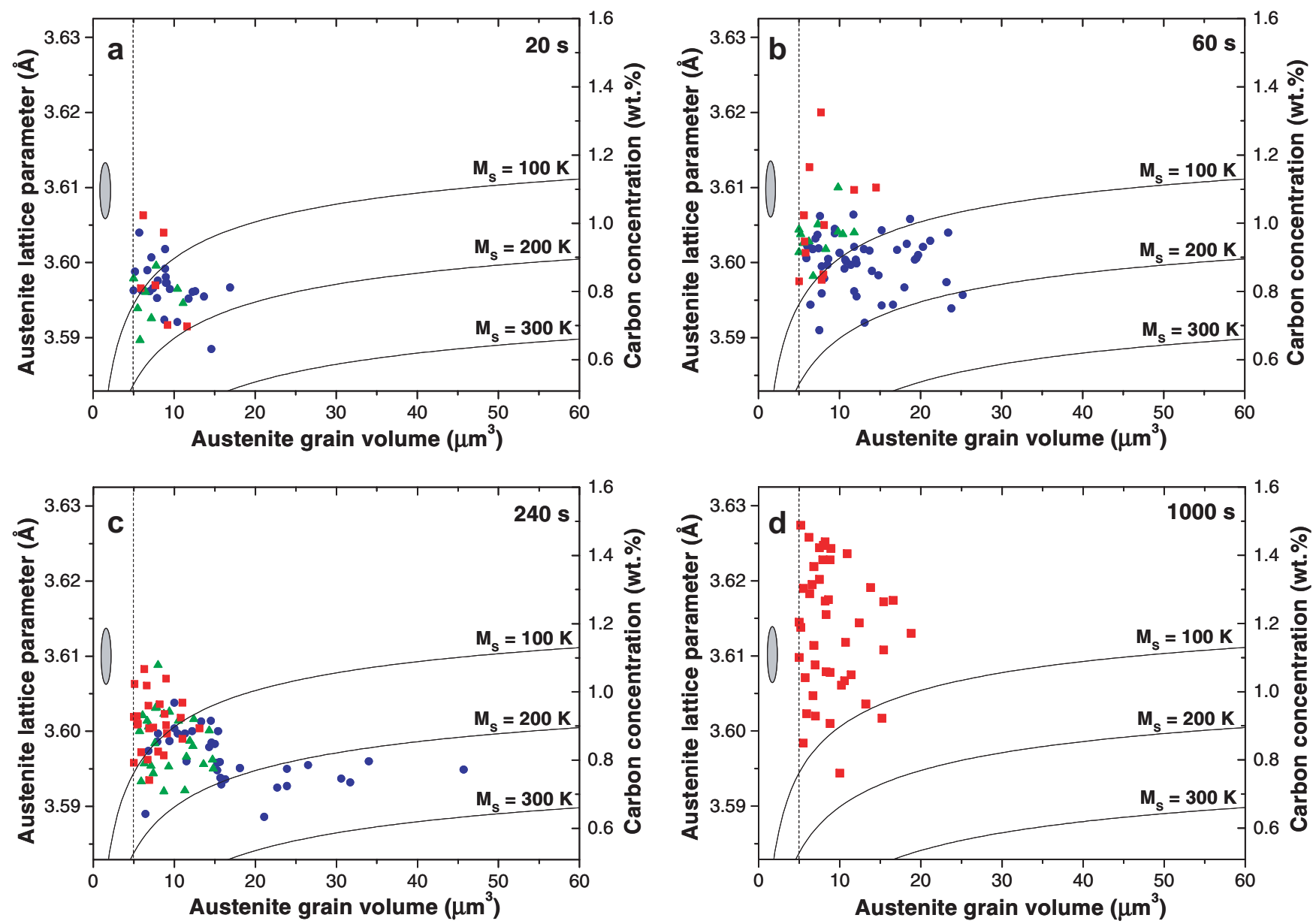

Fig. 6. Lattice parameter and corresponding carbon content of the individual austenite grains as a function of their grain volume for the four bainitic holding times: (a) $20 \mathrm{~s}$, (b) $60 \mathrm{~s}$, (c) $240 \mathrm{~s}$ and (d) $1000 \mathrm{~s}$. The blue circles represent austenite grains that transform in the temperature range of $200<T<300 \mathrm{~K}$, while the green triangles indicate austenite grains that transform in the temperature range of $200<T<100 \mathrm{~K}$. The red squares correspond to the austenite grains that remain stable during cooling to $100 \mathrm{~K}$. The grey area below the detection limit for individual grains of $5 \mu \mathrm{m}^{3}$ (dashed line) represents the very small austenite grains with an experimental average carbon content of about $1.1 \mathrm{wt} . \%$. The solid lines represent the estimates of Eq. (4) for three constant martensitic transformation temperatures $\left(M_{\mathrm{S}}\right)$. A homogeneous carbon concentration of $0.51 \mathrm{wt} . \%$ is present in the austenite grains at the end of the intercritical annealing at $1073 \mathrm{~K}$ [23]. The marker size corresponds to the experimental error.

of the grain volume on its stability, where $M_{\mathrm{S} 0}=702 \mathrm{~K}$ and $B=475 \mu \mathrm{m} \mathrm{K}$ for a multiphase TRIP steel with an aluminium content of $1.750 \mathrm{wt} . \%$ [20]. These values have also been used in the case of the TRIP steel with $0.443 \mathrm{wt} . \% \mathrm{Al}$ in the present study, since the reported change in $M_{\mathrm{S} 0}$ with the aluminium content is only $2 \mathrm{~K} \mathrm{wt.} \%^{-1}$ [35].

Estimates of Eq. (4) succeed in reproducing the boundaries between different stability regions, especially for the $240 \mathrm{~s}$ and $1000 \mathrm{~s}$ samples (see Fig. 6). In the case of the 240 s sample, a significant overlap between different stability regions can be observed. This overlap can be attributed to the role that other microstructural parameters, such as the grain geometrical shape, the dislocation density or the precise nature of the multiphase surroundings of the grain, may play in the stability of the austenite grains. The overlap is much more pronounced in the case of the $20 \mathrm{~s}$ and $60 \mathrm{~s}$ samples. There is a significant number of grains in these samples that should transform between 200 and $100 \mathrm{~K}$, according to their grain volume and carbon con- tent, but are less stable and present a martensitic transformation between 200 and $300 \mathrm{~K}$ (blue circles in Fig. 6a and b). In these two samples, a significant number of austenite grains has already transformed into martensite during the quenching from $673 \mathrm{~K}$ to room temperature, as previously discussed in Section 3.1. Additional local strains due to a preceding martensitic transformation of surrounding grains may cause a shift in the transformation temperature of the neighbouring austenite grains with higher temperatures.

Fig. 7 shows the dependence of the martensitic transformation temperature of the individual austenite grains with their grain volume for the bainitic holding times of 20,60 and $240 \mathrm{~s}$. The experimental data contained in Figs. 6 and 7 indicate that the carbon content constitutes the dominant parameter governing the stability of the largest austenite grains. However, the austenite stability increases significantly with decreasing grain volumes below $15 \mu \mathrm{m}^{3}$, as evidenced by the existence of austenite grains with a 

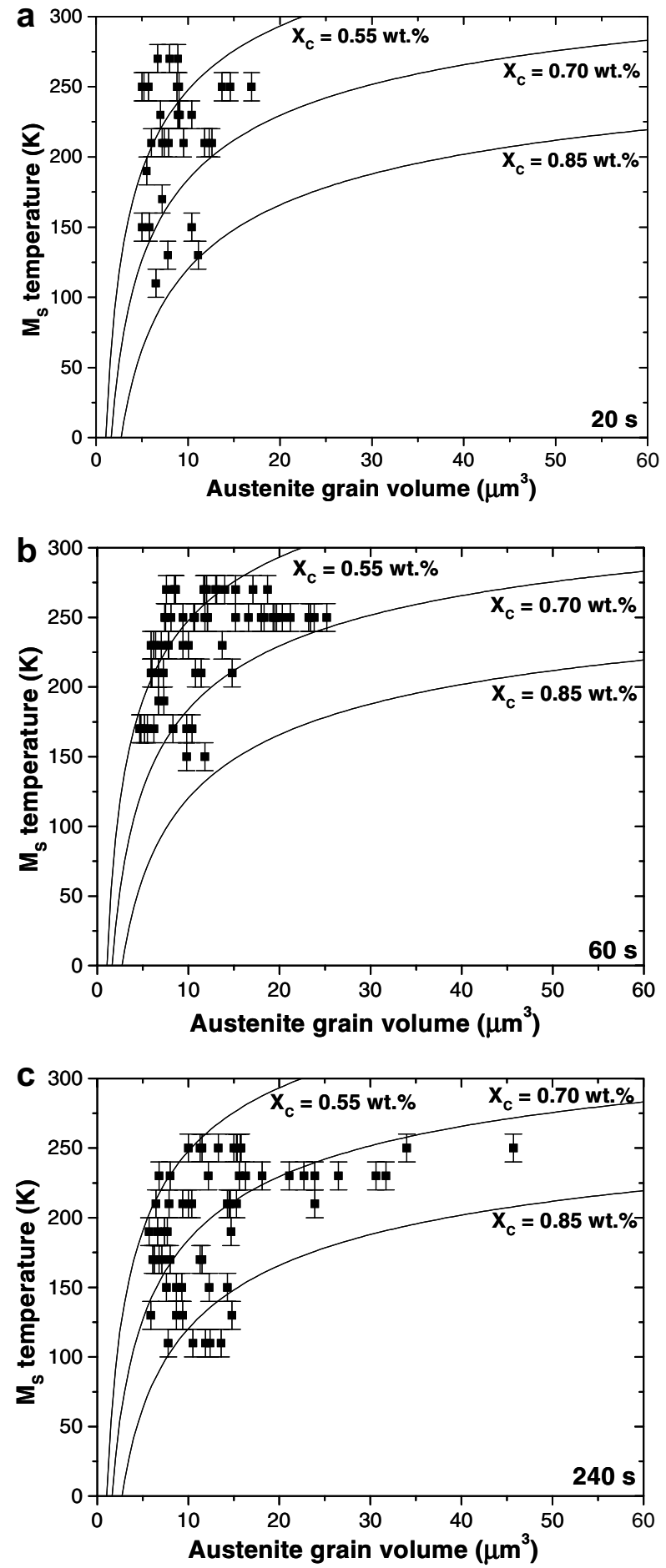

Fig. 7. Martensitic transformation temperature of the individual austenite grains as a function of their grain volume for three bainitic holding times: (a) $20 \mathrm{~s}$, (b) $60 \mathrm{~s}$ and (c) $240 \mathrm{~s}$. The solid lines represent the estimates of Eq. (4) for three constant carbon contents $\left(X_{\mathrm{C}}\right)$.

martensitic transformation temperature lower than $220 \mathrm{~K}$ only below a grain size of $15 \mu \mathrm{m}^{3}$. Fig. 7 also reveals the existence of a critical austenite grain size below which the martensitic transformation with thermal activation cannot take place. This critical value depends only weakly on the carbon content, and is found to be lower than $5 \mu \mathrm{m}^{3}$ for the TRIP materials of this study.

\section{Conclusions}

We have characterized in detail the austenite grain distribution and thermal stability in a low-alloyed TRIP steel as a function of the bainitic holding time, by performing in situ 3-D synchrotron X-ray diffraction experiments during cooling from room temperature down to $100 \mathrm{~K}$. The main conclusions from the present study are:

1. The distributions of the grain volume and carbon content of the austenite grains at room temperature manifest the carbon enrichment at the expense of decreasing the average grain size for longer bainitic holding times. Only the small austenite grains are successfully retained at room temperature for short bainitic holding times, since the bigger grains are too unstable and already transform into martensite above room temperature. Both the grain size and the carbon content play an important role in stabilizing the austenite grains for the longest bainitic holding time of $1000 \mathrm{~s}$. The carbon content in the austenite grains can even reach a value of 1.5 wt. $\%$ at longer holding times. This constitutes a strong carbon enrichment of the austenite grains with respect to their carbon concentration during the intercritical annealing ( $0.51 \mathrm{wt} . \%)$.

2. More than $80 \mathrm{vol} . \%$ of the austenite grains retained at room temperature $\left(V_{\gamma}>5 \mu \mathrm{m}^{3}\right)$ transforms into martensite during cooling to $100 \mathrm{~K}$, with the exception of the $1000 \mathrm{~s}$ sample where all the austenite grains remain untransformed after cooling. Only the austenite grains with a combination of a small volume and a high carbon content are stable enough not to transform into martensite during cooling.

3. Three different transformation behaviours have been observed during cooling: one-step transformation, twostep or incomplete transformation, and non-transforming grains. The fraction of grains that display each of the mentioned transformation behaviours varies significantly with the bainitic holding time. The two-step and incomplete transformation behaviours can be ascribed to two spatially separated parts of an original intercritical austenite grain. The temperature dependence of the lattice parameter in these cases indicates that the part stable at lower temperatures presents a higher carbon content.

4. The lack of additional reflections attributed to the tetragonal symmetry of martensite points to the existence of a critical grain volume below which the martensite structure would remain cubic. Below this critical volume, the reduction in the strain-induced elastic interaction energy will not dominate over the decrease in entropy associated with the ordering of the carbon atoms in the octahedral interstitial sites of the bcc lattice. This observation has important 
consequences for the development of micromechanical models of the martensitic transformation in low-alloyed TRIP steels.

5. The strong differences in the martensitic transformation temperature from grain to grain reveal a distribution in stability within the austenite phase. The carbon content constitutes the dominant parameter governing the stability of the larger austenite grains, while the grain volume strongly influences the austenite stability below $15 \mu \mathrm{m}^{3}$. There exists a critical size below which the thermally activated martensitic transformation will not occur.

\section{Acknowledgements}

We acknowledge the European Synchrotron Radiation Facility for provision of synchrotron radiation facilities and thank L. Margulies for assistance in using beam line ID11. This work was financially supported by the Netherlands Foundation for Fundamental Research on Matter (FOM) and the Netherlands Institute for Metals Research (NIMR).

\section{References}

[1] Militzer M. Science 2002;298:975.

[2] Senuma T. ISIJ Int 2001;6:520.

[3] Jacques P, Furnémont Q, Mertens A, Delannay F. Phil Mag 2001;81:1789.

[4] De Cooman BC. Curr Opin Solid State Mater Sci 2004;8:285.

[5] Zackay VF, Parker ER, Fahr D, Busch R. Trans Am Soc Met 1967;60:252

[6] Chen CH, Era H, Shimizu M. Metall Trans A 1989;20A:437.

[7] Takahashi M, Bhadeshia HKDH. Mater Trans JIM 1991;32:689.

[8] Girault E, Mertens A, Jacques P, Houbert Y, Verlinden B, Van Humbeeck J. Scripta Mater 2001;44:885.

[9] Zaefferer S, Ohlert J, Bleck W. Acta Mater 2004;52:2765.
[10] Timokhina IB, Hodgson PD, Pereloma EV. Metall Mater Trans A 2004;35A:2331.

[11] Sugimoto K, Usui N, Kobayashi M, Hashimoto S. ISIJ Int. 1992;32:1311.

[12] Basuki A, Aernoudt E. Scripta Mater 1999;40:1003.

[13] Zhao L, van Dijk NH, Bruck E, Sietsma J, van der Zwaag S. Mater Sci Eng A 2001;313:145.

[14] Berrahmoune MR, Berveiller S, Inal K, Moulin A, Patoor E. Mater Sci Eng A 2004;378:304.

[15] Jacques PJ, Furnemont Q, Godet S, Pardoen T, Conlon KT, Delannay F. Phil Mag 2006;86:2371.

[16] Goel NC, Chapakravarty JP, Tangri K. Metall Trans A 1987;18A:5.

[17] Sugimoto K, Misu M, Kobayashi M, Shirasawa H. ISIJ Int 1993;33:775.

[18] Kruijver SO, Zhao L, Sietsma J, Offerman SE, van Dijk NH, Margulies L, Lauridsen E, Grigull S, Poulsen HF, van der Zwaag S. Steel Res 2002;73:236.

[19] Turteltaub S, Suiker ASJ. Int J Solids Struct 2006;43:7322.

[20] Jimenez-Melero E, van Dijk NH, Zhao L, Sietsma J, Offerman SE, Wright JP, van der Zwaag S. Scripta Mater 2007;56:421.

[21] Tjahjanto DD, Turteltaub S, Suiker ASJ, van der Zwaag S. Modell Simul Mater Sci Eng 2006;14:617.

[22] Turteltaub S, Suiker ASJ. J Mech Phys Solids 2005;53:1747.

[23] van Dijk NH, Butt AM, Zhao L, Sietsma J, Offerman SE, Wright JP, van der Zwaag S. Acta Mater 2005;53:5439.

[24] Jimenez-Melero E, van Dijk NH, Zhao L, Sietsma J, van der Zwaag S. Adv. X-ray Analysis, submitted for publication.

[25] Warren BE. X-ray diffraction. New York: Dover Publications; 1990.

[26] Scott CP, Drillet J. Scripta Mater 2007;56:489.

[27] Dyson DJ, Holmes B. J Iron Steel Inst 1970;208:469.

[28] Jacques PJ, Ladrière J, Delannay F. Metall Mater Trans A 2001;32A:2759.

[29] Bhadeshia HKDH. Bainite in steels. 2nd ed. Cambridge: IOM Communications Cambridge University Press; 2001.

[30] Pereloma EV, Timokhina IB, Miller MK, Hodgson PD. Acta Mater 2007;55:2587.

[31] Bai DQ, Di Chiro A, Yue S. Mater Sci Forum 1998;284-6:253.

[32] Xiao L, Fan Z, Jinxiu Z, Mingxing Z, Mokuang K, Zhenqi G. Phys Rev B 1995;52:9970.

[33] Fan Z, Xiao L, Jinxiu Z, Mokuang K, Zhenqi G. Phys Rev B 1995;52:9979.

[34] Andrews KW. J Iron Steel Inst 1965;203:721.

[35] Ishida K. J Alloys Comp 1995;220:126. 